\title{
Is femoral artery calcification a sign of mortality in elderly hip fractures?
}

\author{
Özhan Pazarcı (D), Cihat Ekici (D), Kemal Yazıcı (D), Seyran Kılınç (D), Hayati Öztürk (D) \\ Department of Ortbopaedics and Traumatology, School of Medicine, Cumburiyet University, Sivas, Turkey
}

\begin{abstract}
Objectives: It is important to determine the risks of mortality in elderly patients with hip fractures. The aim of this study was to investigate the effect of femoral artery calcification on mortality risk in patients with cemented partial hip prosthesis.

Methods: The study included 145 patients ( $\geq 65$-years-old) with cemented partial hip prosthesis operated following hip fracture. Patients were divided into two groups: Group (1) included those without femoral artery calcification, and Group (2) with femoral artery calcifications observed on direct radiography. Age, gender, duration of hospitalization, time of death and follow-up duration, ASA score, anesthesia type, fracture type, complication and time of operation for patients were compared between two groups.

Results: After exclusion of certain patients due to lack of necessary information in their documents, a total of 116 patients were investigated. The mean age of patients was 81.52 \pm 6.82 . Mean follow-up duration was 35.39 (range: $0-76$ ) months. Three out of 116 patients died after some complications during surgery. Mean time of death after surgery was 21.21 months in Group 1 and 23.86 months in Group 2 ( $\mathrm{p}=0.628$ ).

Conclusion: The results of this study showed that femoral artery calcification in patients with cemented prosthesis due to hip fracture at advanced age had no effect on mortality. However, there is a need for advanced studies with larger patient groups.
\end{abstract}

Keywords: arterial calcification; hip fracture; mortality

Anatomy 2019;13(2):98-101 @2019 Turkish Society of Anatomy and Clinical Anatomy (TSACA)

\section{Introduction}

Vascular calcification is an important marker of atherosclerosis and a result of chronic inflammatory processes. Histopathologically, widespread arterial calcification is associated with coronary artery stenosis. Aortic calcification is accepted as a sensitive marker for atherosclerosis. ${ }^{[1]}$ Osteoporosis and atherosclerosis are commonly found in these patients. ${ }^{[2]}$ Arterial calcification in some regions is associated with fracture risk. ${ }^{[3]}$

In elderly patients, hip fracture and associated complications are public health issues. ${ }^{[4]}$ According to a United States of America based data, 250,000 hip fractures are observed in cases above the age of 65 years each year. ${ }^{[5]}$ The annual mortality rate of those with hip fracture reaches up to $30 \% .{ }^{[6]}$ Patients operated due to hip fracture have many factors that affect mortality and duration of admission, so it is important to define which factors are associated with mortality. ${ }^{[7]}$ Cemented hemiarthroplasty is a reasonable alternative to a fixation device for the treatment of intertrochanteric fractures. ${ }^{[8]}$

Better understanding of the mechanisms behind vascular calcification will open the way for studies which may be beneficial for cardiovascular and bone health. In our study, the aim was to determine whether femoral artery calcification on hip AP radiographs affects mortality in hip fracture cases.

\section{Materials and Methods}

The study included patients treated in our clinic due to hip fractures during 2015 and 2016. The study received local ethics committee permission from Cumhuriyet University (approval number: 2018-12/08). In order to eliminate the effect of treatment type on mortality in the study group, 145 patients of 65 years and older with 
cemented hemiarthroplasty were included in the study. After excluding patients with no available medical history or radiography, a total of 116 patients were included in the study. Patient information was retrospectively assessed. Direct hip AP radiographs were evaluated by two orthopedists together. Group $1(\mathrm{n}=90)$ was defined as patients without femoral artery calcification, while Group 2 ( $n=26)$ was defined as patients with femoral artery calcification (Figure 1). Differences in terms of parameters such as age, sex, duration of admission, operation time, follow-up duration and death time between the groups were investigated. Additionally, information on American Society of Anesthesiologists (ASA) score, comorbid diseases, complications, type of anesthesia, fracture type, operation within the first 48 hours or not and whether the patient survived was evaluated. All patients had cemented partial hip prosthesis operation performed with anterolateral (WatsonJones) approach in supine position.

Statistical analysis was performed by Statistical Package for Social Sciences (SPSS for Windows, version 21.0, Chicago, IL, USA). Chi-square test and Fisher's exact test were used for comparison of categorical data. KolmogorovSmirnov normality analysis was made for comparison of numerical variables. The survival analysis of exitus patients were investigated with the Kaplan-Meier test.

\section{Results}

A total of 116 patients were included to the study (mean age: $81.52 \pm 6.82)$. Of these patients, 49 were males $(42.2 \%)$ and 67 were females (57.8\%). Mean hospital stay was $11.77 \pm 6.81$ days. Mean time to operation of patients was $4.95 \pm 3.5$ days. While 31 patients $(26.7 \%)$ were taken for operation in the first 48 hours, 85 patients $(73.3 \%)$ had operation after the first 48 hours. Mean follow-up duration was 35.39 (range: 0-76) months. According to ASA scoring, the distribution of patients was as follows: ASA I: 4 patients, ASA II: 56, ASA III: 51 and ASA IV: 5 patients. In total, 98 patients were operated under general anesthesia, while 18 patients under spinal anesthesia. 73 patients had fractures in the femur intertrochanteric region, while 43 patients had femur neck fractures. Complications were observed in 3 out of 116 patients ( 2 cases with infection, 1 with implant failure).

There were no differences observed between the groups in terms of gender, ASA score, anesthesia type, fracture type, complications, and surgery within the first 48 hours (Table 1). Additionally, there were no differences between the groups in terms of age, duration of admission, and operation time. With similar follow-up durations, there was no significant difference observed in the mean death duration between the groups (Table 2).

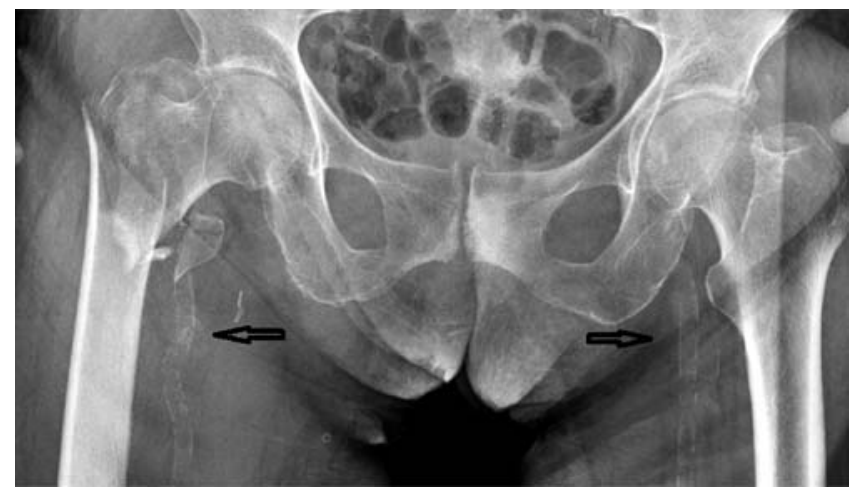

Figure 1. Hip AP radiography of a 90-year old female patient with femoral artery calcification (arrow). (Multifragmentary pertrochanteric fracture, AO classification 31A2.2)

68 patients died during the follow-up period of our study (Figure 2). Fifty of these patients - 4 males (35.29\%) and 26 females (38.23) - were in Group 1 (73.52\%); 18 patients - 10 males (14.70\%) and 8 females (11.76\%) - were in Group 2 (26.47\%). Deaths were related to advanced age and existing comorbidities. There was no correlation between death and arterial calcification between the groups. At least one or more chronic comorbidities were seen in $90 \%$.

\section{Discussion}

The strongest aspect of this study is the presentation of mean 32-month follow-up outcomes of cases with hip fracture both with and without femoral artery calcification. Arterial calcification, cardiovascular diseases and osteoporosis were reported to be related to each other in previ-

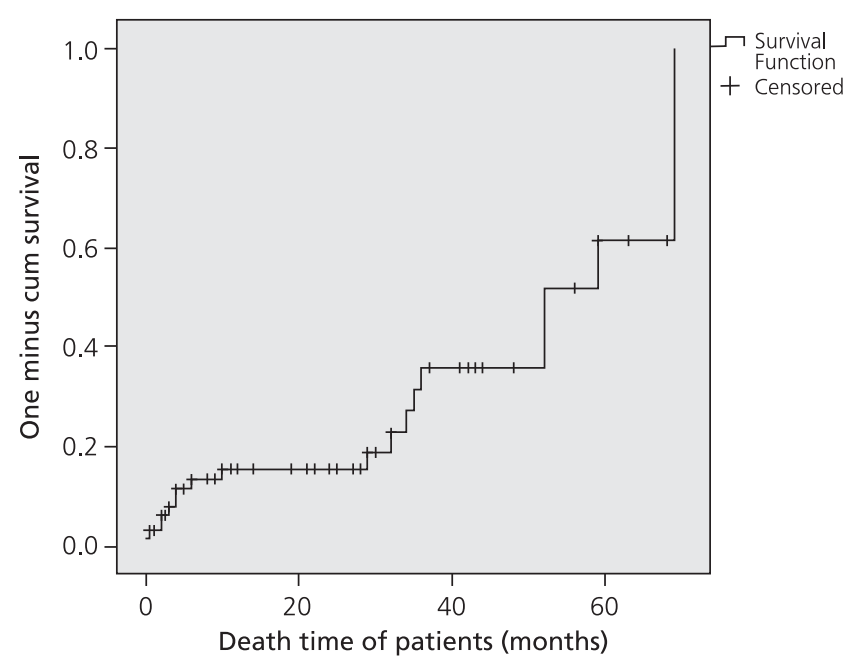

Figure 2. Kaplan-Meier one minus survival curves showing the cumulative death time of patients after hip surgery. 
Table 1

Mortality risk factors compared between groups.

\begin{tabular}{|c|c|c|c|c|c|c|}
\hline \multirow[b]{3}{*}{ Variables } & \multirow[b]{3}{*}{ Category } & \multicolumn{4}{|c|}{ Femoral artery calcification } & \multirow[b]{3}{*}{ p-value } \\
\hline & & \multicolumn{2}{|c|}{$\begin{array}{c}\text { Absent (Group 1) } \\
(n=90)\end{array}$} & \multicolumn{2}{|c|}{$\begin{array}{l}\text { Present (Group 2) } \\
(n=26)\end{array}$} & \\
\hline & & Count & Row N \% & Count & Row N \% & \\
\hline \multirow[t]{2}{*}{ Gender } & Males & 37 & 75.51 & 12 & 24.49 & \multirow{2}{*}{0.647} \\
\hline & Females & 53 & 79.10 & 14 & 20.90 & \\
\hline \multirow[t]{4}{*}{ ASA } & 1 & 2 & 50.00 & 2 & 50.00 & \multirow{4}{*}{0.098} \\
\hline & 2 & 45 & 80.36 & 11 & 19.64 & \\
\hline & 3 & 41 & 80.39 & 10 & 19.61 & \\
\hline & 4 & 2 & 40.00 & 3 & 60.00 & \\
\hline \multirow[t]{2}{*}{ Type of anesthesia } & General & 76 & 77.55 & 22 & 22.45 & \multirow{2}{*}{0.983} \\
\hline & Spinal & 14 & 77.78 & 4 & 22.22 & \\
\hline \multirow[t]{2}{*}{ Fracture type } & Intertrochanteric & 55 & 75.34 & 18 & 24.66 & \multirow{2}{*}{0.45} \\
\hline & Femur neck & 35 & 81.40 & 8 & 18.60 & \\
\hline \multirow[t]{4}{*}{ Complication } & None & 87 & 77.68 & 25 & 22.32 & \multirow{4}{*}{0.781} \\
\hline & Infection & 2 & 66.67 & 1 & 33.33 & \\
\hline & Revision & 0 & 0.00 & 0 & 0.00 & \\
\hline & Other & 1 & 100.00 & 0 & 0.00 & \\
\hline \multirow[t]{2}{*}{ Operation in first 48 hours } & Yes & 27 & 87.10 & 4 & 12.90 & \multirow{2}{*}{0.138} \\
\hline & No & 63 & 74.12 & 22 & 25.88 & \\
\hline
\end{tabular}

ous studies. ${ }^{[0]}$ However, these studies included assessment of aortic calcification. ${ }^{[10]}$ Our study is important in terms of evaluating patients with femoral artery calcification on direct hip radiographies in terms of mortality.

The main effect of vascular calcification in bone is osteoporosis and fragility fracture due to reduced bone turnover ${ }^{[1,12]}$ Aortic calcification is not only associated with lower bone mass but also a higher incidence of new osteoporotic fractures ${ }^{[1,1,14]}$ Peripheral artery calcification is associated with low bone volume and coronary artery calcification. ${ }^{[15,16]}$ No statistically significant difference in mortality rates between two groups was found in our study.

The effect of implant choice for hip fracture on mortality rates of patients was previously investigated by early studies. Cemented or cement-free partial hip prosthesis or proximal femoral nail (PFN) may be used in patients with intertrochanteric fracture. ${ }^{[17]}$ The present study included patients that have been treated with cemented hemiarthroplasty, whereas patients treated with the others were excluded. Internal fixation may also be appropriate for elderly patients with impaired mobility, but further studies are required on this group before definite conclusions can be made. ${ }^{[18]}$

Another superior aspect of our study is the length of the follow-up duration. Mean mortality time of patients in both groups was more than twenty months. The mortality in the first year varies from $10-30 \%$ being the most common period. ${ }^{[19,20]}$ In this study, there was no statisti- cally significant difference in mortality rates after partial hip prosthesis among patients with femoral artery calcification compared to the control group. There were also no statistically significant differences observed between the groups when compared in terms of sex, ASA score, anesthesia type, fracture type, complications and time to surgery between the groups. Advanced age, male sex, cognitive impairment, psychiatric illness, living with a caregiver, having more than two comorbidities, cardiovascular disease, renal disease or any malignancy have been suggested to be associated with high mortality rates in hip fracture patients. ${ }^{[21]}$ In our series, the mean age of the patients was over 80 years (Table 2). Especially for such elderly patients with hip fractures, it is necessary to well define factors that are associated with increased mortality rates to predict life expectancy and to prevent

Table 2

Comparison of patient information in Group $1(n=90)$ and Group 2 $(n=26)$ patients

\begin{tabular}{lccc}
\hline & $\begin{array}{c}\text { Group 1 } \\
\text { Mean } \pm \text { SD }\end{array}$ & $\begin{array}{c}\text { Group 2 } \\
\text { Mean } \pm \text { SD }\end{array}$ & p-value \\
\hline Age (years) & $80.95 \pm 6.93$ & $83.5 \pm 6.14$ & 0.094 \\
Duration of admission (days) & $11.65 \pm 6.2$ & $12.19 \pm 8.72$ & 0.771 \\
Operation time (days) & $5 \pm 3.78$ & $4.8 \pm 2.29$ & 0.806 \\
Death time (months) & $21.21 \pm 18.52$ & $23.86 \pm 23.17$ & 0.628 \\
Follow-up duration (months) & $36.19 \pm 23.04$ & $32.63 \pm 24.46$ & 0.495 \\
\hline
\end{tabular}


complications. ${ }^{[22]}$ This study is important in terms of showing that femoral artery calcification has no effect on increased mortality risk in elderly with hip fractures. Nevertheless, this study has some limitations. Among these are the retrospective nature of the study and the rather limited number of the patient group.

\section{Conclusion}

This study showed that femoral artery calcification in elderly patients with cemented prosthesis has no effect on mortality. However, there is a need for advanced studies with larger patient groups.

\section{References}

1. Abedin M, Tintut Y, Demer LL. Vascular calcification: mechanisms and clinical ramifications. Arterioscler Thromb Vasc Biol 2004;24: 1161-70.

2. Kardos A, Casadei B. Hormone replacement therapy and ischaemic heart disease among postmenopausal women. J Cardiovasc Risk 1999;6:105-12.

3. Cannata-Andia JB, Rodriguez-Garcia M, Carrillo-Lopez N, NavesDiaz M, Diaz-Lopez B. Vascular calcifications: pathogenesis, management, and impact on clinical outcomes. J Am Soc Nephrol 2006; $17:$ S267-73

4. Abrahamsen B, Van Staa T, Ariely R, Olson M, Cooper C. Excess mortality following hip fracture: a systematic epidemiological review. Osteoporos Int 2009;20:1633-50.

5. Negrete-Corona J, Alvarado-Soriano JC, Reyes-Santiago LA. Hip fracture as risk factor for mortality in patients over 65 years of age. Case-control study. [Article in Spanish] Acta Ortop Mex 2014;28: 352-62.

6. Dhanwal DK, Dennison EM, Harvey NC, Cooper C. Epidemiology of hip fracture: worldwide geographic variation. Indian J Orthop 2011;45:15-22.

7. Uludağ Ö, Tutak A, Güler A, Doğukan M, Kaya R, Duran M. Retrospective evaluation of the effects of albumin and hemoglobin values on the duration of hospital stay and mortality in elderly patients operated for hip fracture. [Article in Turkish] Adiyaman Üniversitesi Sağlık Bilimleri Dergisi 2018;4:637-47.

8. Chan KC, Gill GS. Cemented hemiarthroplasties for elderly patients with intertrochanteric fractures. Clin Orthop Relat Res 2000;(371): 206-15.

9. Schulz E, Arfai K, Liu X, Sayre J, Gilsanz V. Aortic calcification and the risk of osteoporosis and fractures. J Clin Endocrinol Metab 2004;89:4246-53.

ORCID ID:

Ö. Pazarcı 0000-0002-2345-0827; C. Ekici 0000-0002-8153-9416; K. Yazıcı 0000-0001-9539-8848; S. Kılınç 0000-0003-0144-0916; H. Öztürk 0000-0003-3273-5565
10. London GM, Marchais SJ, Guérin AP, Boutouyrie P, Métivier F, de Vernejoul MC. Association of bone activity, calcium load, aortic stiffness, and calcifications in ESRD. J Am Soc Nephrol 2008;19: $1827-35$.

11. Cannata-Andia JB, Roman-Garcia P, Hruska K. The connections between vascular calcification and bone health. Nephrol Dial Transplant 2011;26:3429-36.

12. El Maghraoui A, Rezqi A, Mounach A, Achemlal L, Bezza A, Ghozlani I. Relationship between vertebral fracture prevalence and abdominal aortic calcification in men. Rheumatology (Oxford) 2012; 51:1714-20.

13. Naves M, Rodríguez-García M, Díaz-López JB, Gómez-Alonso C, Cannata-Andía JB. Progression of vascular calcifications is associated with greater bone loss and increased bone fractures. Osteoporos Int 2000;19:1161-6.

14. Bagger YZ, Tankó LB, Alexandersen P, Qin G, Christiansen C. Radiographic measure of aorta calcification is a site-specific predictor of bone loss and fracture risk at the hip. J Intern Med 2006;259: 598-605.

15. Adragao T, Herberth J, Monier-Faugere MC, Branscum AJ, Ferreira A, Frazao JM, Dias Curto J, Malluche HH. Low bone volume-a risk factor for coronary calcifications in hemodialysis patients. Clin J Am Soc Nephrol 2009;4:450-5.

16. Coen G, Ballanti P, Mantella D, Manni M, Lippi B, Pierantozzi A, Di Giulio S, Pellegrino L, Romagnoli A, Simonetti G, Splendiani G. Bone turnover, osteopenia and vascular calcifications in hemodialysis patients: a histomorphometric and multislice CT study. Am J Nephrol 2009;29:145-52.

17. Gölge UH, Pazarci O, Kilinç S, Nusran G, Kaymaz B, Göksel F, Kömürcü E, Bulut $O$. The treatment of intertrochanteric fractures comparison of PFN and hemiarthroplasty 3-year mortality study. Acta Orthop Belg 2016;82:508-15.

18. Parker MJ, Khan RJK, Crawford J, Pryor GA. Hemiarthroplasty versus internal fixation for displaced intracapsular hip fractures in the elderly. A randomised trial of 455 patients. J Bone Joint Surg Br 2002; 84:1150-5.

19. Braithwaite RS, Col NF, Wong JB. Estimating hip fracture morbidity, mortality and costs. J Am Geriatr Soc 2003;51:364-70.

20. Johnell O, Kanis JA. An estimate of the worldwide prevalence, mortality and disability associated with hip fracture. Osteoporos Int 2004;15:897-902.

21. Liu $Y$, Wang $Z$, Xiao W. Risk factors for mortality in elderly patients with hip fractures: a meta-analysis of 18 studies. Aging Clin Exp Res 2018;30:323-30.

22. Moran CG, Wenn RT, Sikand M, Taylor AM. Early mortality after hip fracture: is delay before surgery important? J Bone Joint Surg Am 2005;87:483-9.

Correspondence to: Özhan Pazarcı, MD

Department of Orthopaedics and Traumatology, School of Medicine, Cumhuriyet University, Sivas, Turkey

Phone: +903462580638

e-mail: dr.pazarci@gmail.com

Conflict of interest statement: No conflicts declared.

This is an open access article distributed under the terms of the Creative Commons Attribution-NonCommercial-NoDerivs 3.0 Unported (CC BY-NC-ND3.0) Licence (http://creativecommons.org/licenses/by-nc-nd/3.0/) which permits unrestricted noncommercial use, distribution, and reproduction in any medium, provided the original work is properly cited. Please cite this article as: Pazarcı Ö, Ekici C, Yazıcı K, Kılınç S, Öztürk H. Is femoral artery calcification a sign of mortality in elderly hip fractures? Anatomy 2019;13(2):98-101. 